\title{
Anabases
}

ANABASES Traditions et réceptions de l'Antiquité

Katell BERTHELOT, Philanthrôpia judaica. Le débat autour de la " misanthropie » des lois juives dans l'Antiquité

\section{Pierre Cordier}

\section{OpenEdition}

Journals

Édition électronique

URL : http://journals.openedition.org/anabases/1555

DOI : 10.4000/anabases. 1555

ISSN : 2256-9421

Éditeur

E.R.A.S.M.E.

\section{Édition imprimée}

Date de publication : 1 octobre 2005

Pagination : 261-263

ISSN : 1774-4296

\section{Référence électronique}

Pierre Cordier, « Katell BeRTHELOt, Philanthrôpia judaica. Le débat autour de la " misanthropie » des lois juives dans l'Antiquité ", Anabases [En ligne], 2 | 2005, mis en ligne le 01 octobre 2011, consulté le 22 septembre 2020. URL : http://journals.openedition.org/anabases/1555; DOI : https://doi.org/ 10.4000/anabases. 1555

Ce document a été généré automatiquement le 22 septembre 2020

(c) Anabases 


\title{
Katell BERTHELOT, Philanthrôpia judaica. Le débat autour de la " misanthropie » des lois juives dans l'Antiquité
}

\author{
Pierre Cordier
}

\section{RÉFÉRENCE}

Katell BERTHELOT, Philanthrôpia judaica. Le débat autour de la « misanthropie » des lois juives dans l'Antiquité, (Supplements to the Journal for the Study of Judaism, 76), Leiden, E.J. Brill, 2003, 441 p., indices.

149 euros / ISBN 90.04.12886.7

1 Une introduction historiographique nourrie justifie le thème de l'étude : les accusations de misanthropie formulées à l'encontre des Juifs durant l'Antiquité et leur réfutation par les auteurs juifs. L'ouvrage est articulé en deux parties. La première est consacrée aux accusations de misanthropie dirigées contre les Juifs à l'époque hellénistique et romaine. L'analyse du lexique précède l'inventaire et le commentaire des occurrences : parce que la misanthrôpia s'oppose à une valeur positive de l'hellénisme, fréquemment invoquée pour qualifier les dieux, les rois, la cité ou des peuples en particulier, mais aussi parce que la réfutation du grief de misanthropie passe par l'affirmation d'une philanthropie juive, l'auteur commence par étudier l'histoire et l'usage des termes de philanthrôpos et de philoxenos et leurs dérivés avant d'aborder le vocabulaire de la misanthropie (misanthrôpos, apanthrôpos et leurs dérivés, puis misoxenos/ misoxenia). L'accusation de misanthrôpia, associée chez Hécatée d'Abdère et Manéthon au récit de l'expulsion hors d'Égypte, se développe dans un contexte grec chez Lysimaque, Poseidonios, Apollonios Molon, Apion et Philostrate, avant d'être reprise après la guerre de 66-70 ap.J.-C. par Trogue-Pompée, Quintilien, Tacite et Juvénal. Sans 
impliquer nécessairement une hostilité radicale au judaïsme, elle exprime la désapprobation des lois alimentaires ou le refus de participer aux cérémonies païennes et l'idée que les Juifs rejettent les préceptes fondamentaux de l'humanité, tel le partage $\mathrm{du}$ feu et de l'eau. Sous l'influence du stoïcisme, le grief de misanthropie tend ainsi à évoluer d'une observation à caractère ethnographique vers la condamnation morale au nom d'une éthique universaliste. La seconde partie de l'ouvrage est consacrée à la réponse au grief émanant du milieu alexandrin ou romain: la promotion de la philanthrôpia juive chez Philon d'Alexandrie et Flavius Josèphe. Avant ces auteurs, la Lettre d'Aristée, la littérature maccabéenne et le Livre de la Sagesse portent la trace de polémiques entre les Juifs et le milieu ambiant, touchant l'observance des lois alimentaires ou la misoxenia des Égyptiens. L'éthique de Philon n'est pas fondée sur la nature humaine, mais sur l'Écriture. C'est pourquoi il subordonne la philanthrôpia à la piété et la donne pour circonscrite par la Loi, laquelle en définit les bénéficiaires et en exclut les impies. Les occurrences de philanthrôpia chez Flavius Josèphe suggèrent une influence philonienne, mais Josèphe s'attache à réfuter les griefs de misanthropie, et, plus que Philon, met l'accent sur le parallélisme entre les pratiques du judaïsme et les préceptes d'humanité des Bouzygies. La complexité, sinon les contradictions des positions tenues par ces deux auteurs mettent en évidence l'ambiguïté de la littérature apologétique, discours dirigé à la fois vers l'intérieur et vers l'extérieur.

Dans ce livre important, l'érudition de l'auteur n'est jamais gratuite ni pesante et apporte, d'une manière souvent alerte et vive, une avancée significative au dossier de l'antijudaïsme antique. L'ingéniosité remarquable de K. Berthelot dans le commentaire ne laisse pas de trouver parfois ses limites. Lorsque, par exemple, elle lit chez Quintilien, Institution oratoire, III, 7, 18 (p. 160-161) : « et les fondateurs de cités ont une mauvaise cote, s'ils y ont rassemblé une peuplade pernicieuse pour les autres, tel celui qui fut l'initiateur de la superstition juive ", une allusion au séparatisme des pratiques religieuses, il est difficile de se ranger à son interprétation. Bien qu'elle montre une attention rare à la nature et aux conditions de réception des textes qu'elle commente, elle cède, à l'occasion, aux idées reçues de l'exégèse savante qu'elle mobilise. Ainsi les pages qu'elle consacre à Juvénal (p.167-171) tiennent-elles davantage compte des débats sur l'hostilité supposée du satirique aux Orientaux que des caractères propres au genre de la satire, porté à la caricature et aux variations les plus outrées sur des lieux communs. Le parti-pris de faire l'histoire des représentations des pratiques sociales juives, à l'exclusion des débats touchant la réalité vécue de ces pratiques, peut laisser certaines questions en suspens. Parce que K. Berthelot s'en tient aux termes d'une polémique portant sur des représentations, elle tend à présenter comme des faits allant de soi certaines données problématiques, dès lors que l'historien, abandonnant les objets intellectuels des ethnographes et des moralistes, se préoccupe de comportements matériels. Ainsi la notion de kashrut est-elle couramment invoquée pour désigner les règles alimentaires régissant l'alimentation des Juifs et le principe de leur séparatisme. L'appellation est loin d'être absurde, mais les débats normatifs dont la littérature talmudique porte trace supposent des variations de la pratique et, partant, des degrés fort variables de séparatisme, qu'il n'aurait pas été sans intérêt de prendre en compte. La même tendance explique sans doute l'absence, dans la bibliographie, des ouvrages et articles que Simon Mimouni a consacrés au judéochristianisme et au problème des conversions. 


\section{AUTEURS}

\section{PIERRE CORDIER}

Université de Toulouse II-Le Mirail

pierre.cordier@free.fr 